\title{
Estudo in vitro da ação antimicrobiana de extratos de plantas contra Enterococcus faecalis
}

Primeira submissão em 03/02/10 Última submissão em 05/04/10 Aceito para publicação em 06/04/10 Publicado em 20/06/10

\section{In vitro antimicrobial activity of plant extracts against Enterococcus faecalis}

\author{
Edja Maria Melo de Brito Costa ${ }^{1}$; Ariel Siqueira Barbosa ${ }^{2}$; Thulio Antunes de Arruda ${ }^{3}$; \\ Patrícia Teixeira de Oliveira ${ }^{4}$; Fábio Roberto Dametto ${ }^{5}$; Rejane Andrade de Carvalho6; Maria das Dores Melo ${ }^{7}$
}

unitermos
Extratos vegetais
Antibióticos
Ação antimicrobiana
Enterococcus faecalis

\section{resumo}

Introdução: Muitos estudos têm sido realizados para avaliar o potencial terapêutico das plantas. Objetivo: Este estudo teve como objetivo avaliar a ação antimicrobiana dos extratos etanólicos da aroeira-da-praia (Schinus terebinthifolius Raddi), da aroeira-do-sertão (Astronium urundeuva [Fr. All.] Engl.), da ameixa-domato (Ximenia americana L.), da quixabeira (Syderoxylum obtusifolium [Roem et Schult.]) e do hipoclorito de sódio ( $\mathrm{NaOCl}$ a 2,5\%), contra o Enterococcus faecalis (ATCC 29212). Metodologia: Foi realizado teste de difusão em ágar, pelo método do poço, utilizando-se como controle positivo a clorexidina a 0,12\%. Os microrganismos foram semeados em caldo $\mathrm{BHI}$ e incubados a $37^{\circ} \mathrm{C}$ por 24 horas. Posteriormente, as suspensões microbianas foram semeadas em placas Petri, com ágar Mueller Hinton, sendo confeccionados seis poços equidistantes. As placas foram mantidas à temperatura ambiente por 2 horas, para ocorrer a pré-difusão das substâncias, e incubadas a $37^{\circ} \mathrm{C}$ por 48 horas. Foram feitas as análises e medições dos halos de inibição em triplicata e os resultados foram analisados estatisticamente (teste de análise de variância [ANOVA]). Resultados: A quixabeira apresentou os menores halos de inibição (teste $t, p \leq 0,05$ ); por outro lado, a clorexidina a $0,12 \%$ e os extratos vegetais aroeira-do-sertão e aroeira-da-praia, na concentração $100 \%$, induziram halos maiores do que o $\mathrm{NaOCl}$ a 2,5\%, com diferença estatisticamente significativa (teste t, $p \leq 0,05$ ). A aroeira-do-sertão e a aroeira-da-praia apresentaram halos de inibição contra o Enterococcus faecalis superiores aos demais extratos vegetais testados, em todas as concentrações. Conclusão: Todas as substâncias analisadas apresentaram atividade antimicrobiana contra o Enterococcus faecalis, sugerindo que podem representar substâncias alternativas no tratamento endodôntico.

abstract

Introduction: Several studies have evaluated the therapeutic benefits of plants. Objective: The aim of this study was to evaluate the antimicrobial activity of ethanol extracts of pepper tree (Schinus terebinthifolius Raddi), aroeira (Astronium urundeuva [Fr. All.] Engl.), Olacaceae (Ximenia americana L.), quixaba (Syderoxylum obtusifolium [Roem et Schult.]), and sodium hypochlorite ( $\mathrm{NaOCl} 2.5 \%$ ) against Enterococcus faecalis (ATCC 29212). Methods: The agar diffusion test was performed and $0.12 \%$ chlorhexidine was applied as positive control. The microorganisms were allowed to grow in a brain-heart infusion broth (BHI) and incubated at $37^{\circ} \mathrm{C}$ for 24 hours. Subsequently, the microbial suspensions were seeded on Petri dishes containing Mueller Hinton agar, and six equidistant wells were made. The plates were kept at room temperature for 2 hours for the pre-diffusion of substances, and incubated at $37^{\circ} \mathrm{C}$ for 48 hours. The analysis and measurement of inhibition zones were performed in triplicate, and the results were statistically analyzed (ANOVA test). Results: Quixaba produced the smallest inhibition zones ( $t$ test, $\mathrm{p} \leq 0.05$ ). On the other hand, $0.12 \%$ chlorhexidine, herbal extracts of pepper tree and aroeira at 100\% concentration induced larger inhibition zones in comparison with $2.5 \% \mathrm{NaOCl}$, with statistically significant difference ( $t$ test, $\mathrm{p} \leq 0.05$ ). At all concentrations, both pepper tree and aroeira showed a higher inhibition zone against Enterococcus faecalis in comparison with the other plant extracts tested. Conclusion: All the substances analyzed showed antimicrobial activity against E. faecalis. Therefore, they may represent alternative substances in endodontic treatment. key words

Plant extracts

Antibiotics

Antimicrobial action

Enterococcus faecalis

1. Doutora; professora do curso de mestrado em Odontologia da Universidade Estadual da Parába (UEPB).

2. Graduando; estudante de Iniciação Científica da UEPB.

3. Doutor; professor do curso de mestrado em Odontologia da UEPB.

4. Doutora; professora do curso de mestrado em Odontologia da Universidade Potiguar (UnP).

5. Doutor; professor do curso de mestrado em Odontologia da UnP.

6. Doutora; professora do curso de mestrado em Odontologia da UnP.

7. Doutora; professora do curso de Ciências Biológicas da UnP.

Suporte financeiro: Conselho Nacional de Desenvolvimento Científico e Tecnológico (CNPq). 


\section{Introdução}

A importância clínica de infecções por espécies do gênero Enterococcus tem estimulado o desenvolvimento de pesquisas, no sentido de identificar e controlar a sua ocorrência ${ }^{(9,15)}$. Entre as espécies, as principais causadoras de infecção no homem são o Enterococcus faecalis e o Enterococcus faecium, representando cerca de $85 \%$ a $90 \%$ e $5 \%$ a $10 \%$, respectivamente, dos enterococos isolados na clínica. O E. faecalis, além de ser o mais frequente, apresenta resistência natural a diversos antimicrobianos ${ }^{(38)}$.

As espécies de enterococos são encontradas comumente no trato gastrointestinal, no entanto podem ser isoladas em outros sítios, como cavidade bucal, vesícula biliar, vagina e uretra masculina ${ }^{(18)}$. Em odontologia, a presença desta bactéria no interior de canais tem sido associada às infecções endodônticas persistentes, o que tem induzido o desenvolvimento de pesquisas para avaliar a efetividade da ação antimicrobiana de medicamentos intracanais contra este microrganismo ${ }^{(8,10,19)}$.

A persistência das infecções endodônticas tem sido atribuída à permanência de bactérias em áreas de difícil acesso, como lacunas de reabsorção, cemento, canais laterais e deltas, túbulos dentinários e lesão perirradicu$\operatorname{lar}^{(34)}$. Esses sítios propiciam o abrigo de microrganismos, ficando protegidos da ação da solução irrigadora e dos instrumentos endodônticos, contribuindo para a persistência da infecçãa ${ }^{(30)}$. Nesse contexto, a lesão periapical é mantida por microrganismos que residem no sistema de canais radiculares de dentes afetados, sendo sua resolução dependente da remoção do agente irritante por meio da limpeza e obturação do canal radicular(7).

Nos últimos anos tem sido observado um crescente interesse da comunidade científica pelas plantas medicinais e pela fitoterapia, por apresentarem potenciais terapêuticos e econômicos visados, especialmente, pela indústria farmacêutica, que realiza a prospecção de novos produtos, com menos efeitos indesejáveis do que os fármacos já existentes ${ }^{(1,4,5,21,23-26,30,36,38)}$.

O presente estudo teve como objetivo avaliar a ação antimicrobiana de quatro tipos de extratos vegetais e de soluções utilizadas na clínica odontológica sobre o $E$. faecalis.

\section{Material e métodos}

Foram utilizados extratos de quatro espécies vegetais: aroeira-da-praia (Schinus terebinthifolius Raddi), aroeira-do- sertão (Astronium urundeuva [Fr. All.] Engl.), ameixa-do-mato (Ximenia americana L.), quixabeira (Syderoxylum obtusifolium [Roem et Schult.]), em diferentes concentrações (100\%, $50 \%, 25 \%, 12,5 \%$ e $6,25 \%)$, hipoclorito de sódio a 2,5\% e clorexidina a $0,12 \%$ (controle positivo).

O extrato de cada planta foi obtido pela imersão rápida em etanol sob ebulição, sendo, em seguida, fracionado e dessecado à sombra em área específica. Posteriormente, o extrato foi pesado $(250 \mathrm{~g})$ e acondicionado em um liquidificador. Então, foram vertidos $500 \mathrm{ml}$ do solvente (álcool etílico hidratado), dando início ao processo de extração sob turbilhonamento durante 10 minutos seguidos de condicionamento em cristalizadores, para deixar macerar durante 72 horas, sob agitação frequente, em temperatura ambiente. Passado o tempo, realizaram-se os processos de expressão, filtração, correção do volume final dos extratos etanólicos para $250 \mathrm{ml}$ e acondicionamentos em vidros de cor âmbar, à temperatura ambiente.

A cepa indicadora foi o Enterococcus faecalis, procedente da American Type Culture Collection (ATCC 29212). Os microrganismos foram semeados em caldo brain heart infusion (BHI, Difco), obedecendo às suas características fisiológicas, sendo incubados a $37^{\circ} \mathrm{C}$ por 24 horas. Após esse período, padronizaram-se os inóculos de acordo com o tubo 1 da escala de McFarland, que foram semeados em ágar Mueller Hinton (Difco) para comprovar a "pureza" da cultura. Obtidos os extratos, preparou-se o ágar Mueller Hinton, o qual foi distribuído em placas de Petri de $140 \mathrm{~mm}$ de diâmetro, com volume suficiente para atingir uma espessura de $5 \mathrm{~cm}$. Após a solidificação, por meio da técnica de semeadura de superfície, as suspensões microbianas foram inoculadas em cada placa, com auxílio do swab, em três sentidos: horizontal, vertical e diagonal, para evitar o crescimento de colônias isoladas. Posteriormente, foram confeccionados, em cada placa de Petri, seis poços no ágar, utilizando-se seringa de insulina, de forma a padronizar o diâmetro da perfuração.

Com uma seringa de insulina, os poços foram preenchidos em quantidade suficiente para o seu preenchimento. Mantiveram-se as placas de Petri à temperatura ambiente por 2 horas, para ocorrer a pré-difusão das substâncias, e foram, posteriormente, incubadas a $37^{\circ} \mathrm{C}$ por 48 horas. Transcorrido o tempo, as placas de Petri foram analisadas, sendo medidos, em milímetros, os halos de inibição do crescimento microbiano formados no ágar.

Os ensaios foram realizados em triplicata e o resultado final foi determinado pela média aritmética dos halos de inibição. O teste de análise de variância (ANOVA) foi usado para a análise estatística. 


\section{Resultados}

Dos extratos vegetais analisados, a aroeira-do-sertão e a aroeira-da-praia apresentaram os maiores halos de inibição, com diferença estatisticamente significativa (teste $t, p \leq 0,05$ ) na maioria das concentrações (Tabela). Não se observou diferença significativa quando os extratos da aroeira-dapraia foram comparados com os da ameixa-do-mato, nas concentrações de $50 \%$, $25 \%$ e $12,5 \%$, nem quando se compararam os halos de inibição dos extratos da aroeirada-praia e da aroeira-do-sertão em todas as concentrações $(p \geq 0,05)$.

A quixabeira apresentou os menores halos de inibição, com atividade antimicrobiana apenas nas concentrações de $100 \%$ e $50 \%$ (Figura 1); por outro lado, as soluções da aroeira-do-sertão, nas diferentes concentrações, apresentaram os maiores halos (Figura 2).

A clorexidina a $0,12 \%$ e os extratos vegetais da aroeirado-sertão e da aroeira-da-praia na concentração 100\% induziram halos maiores do que o hipoclorito de sódio a 2,5\%, com diferença estatisticamente significativa $(p \leq 0,05)$. Os halos produzidos pela aroeira-do-sertão e pela aroeira-dapraia, na concentração de $50 \%$, foram menores do que aqueles do hipoclorito de sódio a 2,5\%, sem diferença estatisticamente significativa. $O$ controle positivo, solução de clorexidina a $0,12 \%$, apresentou atividade antimicrobiana superior a todas as substâncias testadas $(p \leq 0,05)$.

\section{Discussão}

Na odontologia, a presença do E. faecalis no interior de canais tem sido associada às infecções endodônticas persistentes $^{(31)}$, o que tem induzido o desenvolvimento de pes-

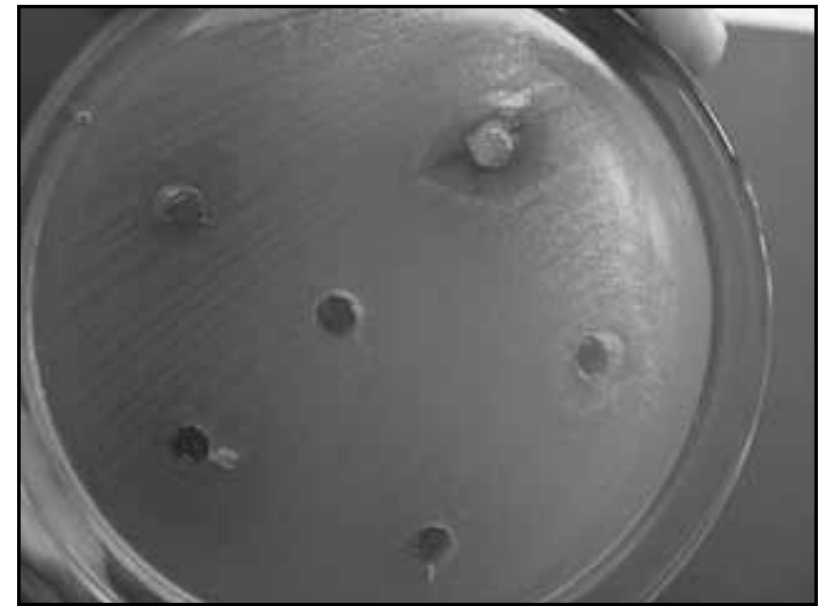

Figura 1 - Teste de sensibilidade da cultura de E. faecalis (ATCC 29212) ao extrato de quixabeira (Syderoxylum obtusifolium [Roem et Schult.]) no ágar Muller-Hinton (Difco), decorridas 48 horas de incubação a $37^{\circ} \mathrm{C}$

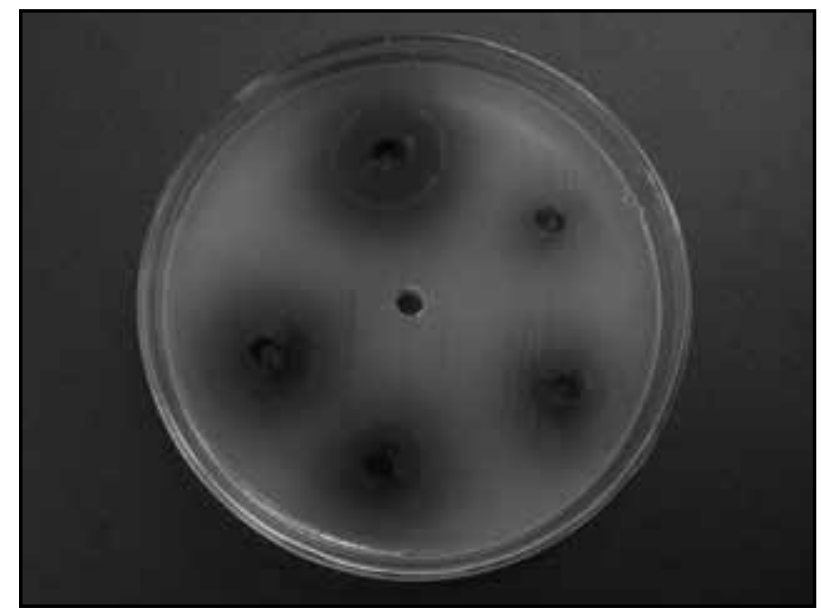

Figura 2 - Teste de sensibilidade da cultura de E. faecalis (ATCC 29212) ao extrato de aroeira-do-sertão (Astronium urundeuva [Fr. All.] Engl.) no ágar Muller-Hinton (Difco), decorridas 48 horas de incubação a $37^{\circ} \mathrm{C}$

quisas para avaliar a efetividade da ação antimicrobiana de medicamentos intracanais diante desse microrganismo ${ }^{(10,19)}$.

\begin{tabular}{|c|c|c|c|c|c|c|c|}
\hline $\begin{array}{cc} & \text { Méd } \\
\text { Tabela } & \text { dife }\end{array}$ & $\begin{array}{l}\text { os halo } \\
\text { es conc }\end{array}$ & $\begin{array}{l}\text { ibição, e } \\
\text { ôes, sobr }\end{array}$ & $\begin{array}{l}\text { metros } \\
\text { terococ }\end{array}$ & $\begin{array}{l}\text { ste de dif } \\
\text { ecalis, de }\end{array}$ & $\begin{array}{l}0 \text { das subs } \\
\text { ridas } 48 \text { h }\end{array}$ & $\begin{array}{l}\text { as testadas } \\
\text { le incubaç }\end{array}$ & a $37^{\circ} \mathrm{C}$ \\
\hline \multirow{2}{*}{$\begin{array}{c}\text { Concentração } \\
(\%)\end{array}$} & \multicolumn{7}{|c|}{ Substâncias } \\
\hline & $\begin{array}{l}\text { Aroeira- } \\
\text { da-praia }\end{array}$ & $\begin{array}{l}\text { Aroeira- } \\
\text { do-sertão }\end{array}$ & $\begin{array}{l}\text { Ameixa- } \\
\text { do-mato }\end{array}$ & Quixabeira & $\begin{array}{l}\text { Clorexidina } \\
\text { alcoólica }\end{array}$ & $\begin{array}{c}\text { Clorexidina } \\
\text { aquosa }\end{array}$ & $\begin{array}{l}\text { Hipoclorito } \\
\text { de sódio }\end{array}$ \\
\hline 100 & 18,91 & 19,45 & 16,52 & 12,61 & - & - & - \\
\hline 50 & 16,32 & 16,51 & 14,61 & 10,2 & - & - & - \\
\hline 25 & 13,93 & 15,03 & 14,14 & 0 & - & - & - \\
\hline 12,5 & 13,08 & 13,21 & 11,71 & 0 & - & - & - \\
\hline 6,25 & 11,41 & 11,27 & 9,75 & 0 & - & - & - \\
\hline 2,5 & - & - & - & - & - & - & 17,07 \\
\hline 0,12 & - & - & - & - & 24,52 & 23,73 & - \\
\hline
\end{tabular}


Todas as concentrações dos extratos da aroeira-dapraia analisados neste estudo mostraram ação antimicrobiana contra o $E$. feacalis. Outros estudos têm demonstrado a atividade antimicrobiana desse vegetal contra diversos tipos de microrganismos da cavidade bucal ${ }^{(20,23)}$. No entanto, em nenhum desses estudos o $E$. faecalis foi incluído entre as cepas analisadas, o que impossibilita a comparação dos resultados encontrados no presente estudo. Martinez Guerra et al. ${ }^{(23)}$ avaliaram a ação de extratos de aroeirada-praia em diferentes concentrações e evidenciaram atividade antimicrobiana contra bactérias Gram-positivas, Gram-negativas e fungos do gênero Candida em todas as concentrações. Resultados positivos também foram encontrados no trabalho de Martinez et al. ${ }^{(23)}$ com a aroeira-da-praia nas concentrações de $100 \%$ e $50 \%$. Por outro lado, na concentração de $10 \%$ não se observou ação antimicrobiana contra bactérias Gram-positivas e Gram-negativas, diferente do presente estudo, em que a aroeira-da-praia demonstrou atividade antimicrobiana em todas as concentrações analisadas, com variação de $100 \%$ a 6,25\%. Em função da sua propriedade antimicrobiana, a aroeira-da-praia tem sido indicada no tratamento de estomatite e inflamações bucais, além de traumatismos causados por próteses mal adaptadas ${ }^{(39)}$.

A ameixa-do-mato, neste estudo, apresentou atividade antimicrobiana em todas as concentrações testadas, tendo, no entanto, exibido halos de inibição menores do que aqueles produzidos pela aroeira-da-praia e aroeirado-sertão. Outros estudos têm observado atividade antimicrobiana da ameixa-do-mato(17, 28), tendo verificado que o extrato das raízes desse vegetal fica entre os 10 que apresentam maior atividade contra Enterococcus faecalis e Streptococcus pyogenes. Omer e Elnima ${ }^{(28)}$ testaram as atividades antimicrobiana e antifúngica dos extratos clorofórmicos, metanólicos e aquosos da casca do caule, das folhas e das raízes da ameixa-do-mato e concluíram que o extrato metanólico foi o mais ativo. Recentemente, foi observada ação antimicrobiana de extratos aquosos e metanólico desse vegetal contra Staphylococcus aureus, Salmonella typhi, Escherischia coli, Shigella flexneri e Klebsiella pneumoniae ${ }^{(16)}$.

A atividade antimicrobiana da ameixa-do-mato pode ser parcialmente atribuída aos seus constituintes químicos, como os taninos, que vêm sendo tradicionalmente usados, principalmente, para a proteção de superfícies inflamadas. A presença de polifenóis pode ser um forte indicativo de suas atividades anti-inflamatória, antialérgica, antibacteriana, antifúngica, além de seus efeitos vasoprotetores ${ }^{(6)}$.
Diferente dos demais extratos, ainda não foram encontrados estudos que demonstrem a atividade antimicrobiana da quixabeira, especialmente contra o E. faecalis. Por outro lado, estudos têm sido publicados revelando as propriedades terapêuticas dessas plantas ${ }^{(32)}$.

O hipoclorito de sódio, devido às suas propriedades, destaca-se entre as diferentes substâncias irrigadoras auxiliares no preparo químico-mecânico dos canais radiculares, fato que fica evidente a partir do momento em que os profissionais do mundo inteiro a utilizam como primeira opção para irrigação durante o tratamento endodôntico ${ }^{(3)}$. A boa aceitação dessa solução para irrigação deve-se à sua capacidade de dissolver tecidos orgânicos, ser antimicrobiana, possuir $\mathrm{pH}$ alcalino, promover o clareamento, ser desodorizante e ter baixa tensão superficial| ${ }^{(35)}$. Apesar de ter uma atividade antimicrobiana de amplo espectro, com potencial para eliminar bactérias vegetativas, esporos bacterianos, fungos, protozoários e vírus( ${ }^{(34)}$, no presente estudo o hipoclorito de sódio a 2,5\% apresentou atividade antimicrobiana contra o E. faecalis menor que a da aroeira-da-praia e da aroeira do sertão, na concentração de $100 \%$, com diferença estatisticamente significativa.

Nenhuma substância testada neste estudo produziu halo de inibição maior do que aquele produzido pelo controle positivo, a clorexidina a $0,12 \%$. O poder antimicrobiano da clorexidina contra o $E$. faecalis situado nos túbulos dentinários e no canal radicular tem sido comprovado em vários estudos $^{(2,11)} \mathrm{Na}$ terapia endodôntica, a clorexidina tem sido usada como substância química auxiliar ao preparo químico-mecânico ${ }^{(12,14)}$ e como medicação intracanal|(13), apresentando bons resultados apesar de não dissolver tecidos pulpares remanescentes ${ }^{(12,27)}$.

\section{Conclusão}

Constatou-se a presença de atividade antimicrobiana contra o $E$. faecalis em todos os extratos vegetais analisados, cujos halos de inibição foram menores do que os produzidos pela clorexidina a $0,12 \%$.

Os resultados deste estudo sugerem que as plantas analisadas podem representar novas opções no arsenal de substâncias antimicrobianas, sendo necessário o desenvolvimento de mais pesquisas para comprovação da sua eficácia e aplicabilidade clínica, especialmente como substância auxiliar no preparo químico-mecânico de canais radiculares submetidos a tratamento endodôntico. 


\section{Referências}

1. AMORIM, M. M. R.; SANTOS, L. C. Tratamento da vaginose bacteriana com gel vaginal de aroeira (Schinus terebinthifolius Raddi): ensaio clínico randomizado. Rev Bras Ginecol Obstet, v. 25, n. 2, p. 95-102, 2003.

2. BERBER, V. B. Verificação da redução de Enterococcus faecalis no canal radicular e nos túbulos dentinários utilizando diferentes substâncias químicas auxiliares e técnicas de instrumentação: estudo in vitro. 2005. Dissertação (Mestrado em Clínica Odontológica) Faculdade de Odontologia de Piracicaba, Universidade Estadual de Campinas, Piracicaba.

3. BORIN, G.; BECKER, A. N.; OLIVEIRA, E. P. M. A história do hipoclorito de sódio e a sua importância como substância auxiliar no preparo químico mecânico de canais radiculares. Rev Endod Pesq Ens on-line, n. 5, p. 1-5, 2007.

4. BRANCO NETO, M. L. C. et al. Avaliação do extrato hidroalcoólico de aroeira (Schinus terebinthifolius Raddi) no processo de cicatrização de feridas em pele de ratos. Acta Cir Bras, v. 21, suplemento 2, p. 17, 2006.

5. BRANDÃO, M. G. L. etal. Medicinal plants and other botanical products from the Brazilian Official Pharmacopoeia. Rev Bras Farmacogn, n. 16, v. 3, p. 408-20, 2006.

6. BRASILEIRO, M. T. et al. Ximenia americana L.: botânica, química e farmacologia no interesse da tecnologia farmacêutica. Rev Bras Farm, v. 89, n. 2, p. 164-7, 2008.

7. COHEN, S.; BURNS, R. C. Pathways of the pulp. 6. ed. St. Louis: Mosby, 1994. 753p.

8. COSTA, E. M. M. B et al. Avaliação da ação antimicrobiana da própolis e de substâncias utilizadas em endodontia sobre o Enterococcus faecalis. Pesq Bras Odontoped Clin Integr, v. 8, n. 1, p. 21-5, 2008.

9. d'AZEVEDO, P. A. et al. Avaliação de um sistema automatizado na identificação de espécies de Enterococcus. J Bras Patol Med Lab, v. 40, n. 4, p. 237-9, 2004.

10. DOTTO, S. R. et al. Avaliação da ação antimicrobiana de diferentes medicações usadas em endodontia. Rev Odonto Ciênc, v. 21, n. 53, p. 266-9, 2006.

11. ERCAN, E. et al. Antibacterial activity of $2 \%$ chlorhexidine gluconate and $5.25 \%$ sodium hypochlorite in infected root canal: in vivo study. J Endod, v. 30, p. 84-7, 2004.

12. FERRAZ, C. C. R. et al. In vitro assessment of the antimicrobial action and mechanical ability of chlorhexidine gel as an endodontic irrigant. J Endod, v. 7, p. 452-5, 2001.

13. GOMES, B. P. et al. Evaluation of time required for recontamination of coronally sealed canals medicated with calcium hydroxide and chlorhexidine. Int Endod J, v. 36, p. 604-9, 2003.

14. GOMES, B. P. et al. In vitro antimicrobial activity of several concentrations of sodium hypochlorite and chlorhexidine gluconate in the elimination of Enterococcus faecalis. Int Endod J, v. 34, n. 6, p. 424-8, 2001.

15. HÖRNER, R. et al. Suscetibilidade antimicrobiana entre amostras de Enterococcus isoladas no Hospital
Universitário de Santa Maria. J Bras Patol Med Lab, v. 41, n. 6, p. 391-5, 2005.

16. JAMES, D. B. et al. Phytochemical and antimicrobial investigation of the aqueous and methanolic extracts of Ximenia americana. J Med Sci, v. 2, p. 284-8, 2007.

17. KONÉ, W. N. et al. Tradicional medicine in North Cote d' Ivoire: screening of 50 medicinal plants or antibacterial activity. J Ethnopharmacol, v. 93, p. 43-9, 2004.

18. KONEMAN, E. W. et al. Diagnóstico microbiológico: texto e atlas colorido. 5. ed. Rio de Janeiro: MEDSI, 2001. 1488p.

19. KOPPER, P. M. P. et al. Avaliação, in vitro, da atividade antimicrobiana de três cimentos endodônticos. Rev Odonto Ciênc, v. 22, n. 56, p. 106-11, 2007.

20. LIMA, E. O. et al. Schinus terebenthifolius Raddi: avaliação do espectro de ação antimicrobiana de seu extrato aquoso. Infarma, v. 16, n. 7-8, p. 83-5, 2004.

21. LIMA, M. R. F. et al. Anti-bacterial activity of some Brazilian medicinal plants. J Ethnopharmacol, v. 21, p. 137-47, 2006.

22. MARTÍNEZ GUERRA, M. J. et al. Actividad antimicrobiana de un extracto fluido al $80 \%$ de Schinus terebinthifolius Raddi (Copal). Rev Cubana Plant Med, v. 5, n. 1, p. 23-5, 2000.

23. MARTINEZ, M. J. et al. Screening of some Cuban medicinal plants for antimicrobial activity. J Ethnopharmacol, v. 52, p. 171-4, 1996

24. MEDEIROS, K. C. P. et al. Effect of the activity of the Brazilian polyherbal formulation: Eucalyptus globulus Labill, Peltodon radicans Pohl and Schinus terebinthifolius Radd in inflammatory models. Rev Bras Farmacogn, v. 17, n. 1, p. 23-8, 2007.

25. MELO JUNIOR, E. J. M. et al. Estudo de plantas medicinais com atividade antimicrobiana sobre microrganismos presentes na alveolite. Rev $A B O N a c, v .8$, n. 4, p. 220-6, 2000.

26. MELO JUNIOR, E. J. M. et al. Medicinal plants in the healing of dry socket inrats: microbiological and microscopic analysis. Phytomedicine, v. 9, p. 109-16, 2002.

27. OKINO, L. A. et al. Dissolution of pulp tissue by aqueous solution of chlorhexidine digluconate and chlorhexidine digluconate gel. Int Endod J, v. 37, p. 38-41, 2004.

28. OMER, M. E. F. A.; ELNIMA, E. I. Antimicrobial activity of Ximenia americana. Fitoterapia, v. 74, p. 122-6, 2003.

29. PETERS, L. B.; WESSELINK, P. R.; MOORER, W. R. The fate and the role of bacteria left in root dentinal tubules. Int Endod J, v. 28, n. 2, p. 95-9, 1995.

30. RIBAS, M. O. et al. Efeito da Schinus terebinthifolius Raddi sobre o processo de reparo tecidual das lesões ulceradas induzidas na mucosa bucal do rato. Rev Odonto Ciênc, v. 21, n. 53, p. 245-52, 2006.

31. SAFAVI, K. E.; SPANGBERG, L. S. W.; LANGELAND, K. Root canal dentinal tubule desinfection. J Endod, v. 16, n. 5, p. 207-10, 1990.

32. SILVA, G. M. C. et al. Estudo autoecológico de Bumelia sertorium (quixabeira) - Espécie ameaçada de extinção no ecossistema. Caatinga Rev Biol Cien da Terra, v. 4, 
n. 1, 2004. Disponível em: <http://eduep.uepb.edu. $\mathrm{br} / \mathrm{rbct} / \mathrm{sumarios} / \mathrm{pdf} / \mathrm{sertorium}$.pdf $>$. Acesso em: 6 set. 2009.

33. SIQUEIRA Jr., J. F. Aetiology of root canal treatment failure: why well-treated teeth can fail. Int Endod J, v. 34, n. 1, p. 1-10, 2001.

34. SIQUEIRA Jr, J. F. et al. Antibacterial effects of endodontic irrigants on black pigmented Gram-negative anaerobes and facultative bacteria. J Endod, v. 24, n. 6, p. 414-6, 1998.

35. SIQUEIRA, E. L. et al. Influência do pH sobre a estabilidade química da solução de hipoclorito de sódio a 0,5\%. RPG, v. 9, n. 3, p. 207-11, 2002.

36. SPONCHIADO JÚNIOR, E. C. Atividade antibacteriana contra o Enterococcus faecalis de uma medicação intracanal contendo ativos fitoterápicos de Pothomorphe umbellata. 2006. 136f. Tese (Doutorado em Biotecnologia) - Universidade Federal do Amazonas, Manaus.

37. TAVARES, W. Bactérias Gram-positivas problemas: resistência do estafilococo, do enterococo e do pneumococo aos antimicrobianos. Rev Soc Bras Med Trop, v. 33, n. 3, p. 281-301, 2000.

38. TÔRRES A. R. et al. Estudo sobre o uso de plantas medicinais em crianças hospitalizadas da cidade de João Pessoa: riscos e benefícios. Rev Bras Farmacogn, v. 15, n. 4, p. 373-80, 2005.

39. XAVIER FILHO, L.; XAVIER, M. N.; RAMOS, I. N. C. A fitoterapia no combate às afecções bucais. João Pessoa: Editora Idéia, 1995. 287p. 